\title{
INTER-FIRM INFORMATION SHARING IN ENTERPRISE RESOURCE PLANNING SYSTEMS: A CALL FOR TIMELY BUT LIMITED ACCESS TO CUSTOMER INFORMATION
}

\author{
Michael E. Busing \\ Computer Information Systems and Operations Management Program \\ James Madison University \\ MSC 0202, Harrisonburg, VA 22807 USA
}

\begin{abstract}
Current trends in Enterprise Resource Planning (ERP) suggest that supply chain management and tight control over scheduling jobs within the supply chain are key tactical planning issues. Modern ERP software packages, in conjunction with the World Wide Web, allow for automated exchange of information within a company and also between two or more companies (i.e., conveyance of customer information to supplier(s) of parts and components) for the purposes of effective planning and control. While ease of information exchange between a customer and supplier is increasingly critical to the success of modern-day planning and control efforts, the issue of information security is also a very real concem. Suppliers can benefit from gaining access to a customer's dispatch list and material requirements plan (MRP) in order to determine real-time priority of jobs in queue at various work centers within their own organization. Other customer information, however, should remain secure and unavailable to supplier firms for competitive reasons such as threat of forward integration. This paper presents a previously tested priority-sequencing rule that explicitly considers downstream shop conditions in determining which job to nun next. The rule proves to perform well on mean flow time and lateness as well as on variability of these measures. The rule is extended here to incorporate the case where a downstream work center is outside official corporate boundaries. With the call for free exchange of information comes the threat of other, perhaps proprietary, information being accessed by vendors or others outside the official corporate boundaries. The paper will propose information that should be freely exchanged between customers and suppliers and information that should remain secure. Finally, practical measures to manage access to web-enabled ERP information will be proposed.
\end{abstract}

\section{INTRODUCTION}

Review of the dispatching research for job shops indicates that this is a problem that has been studied for over four decades. Dispatching is generally defined as a procedure that uses logical and simple decision rules to determine the priority of jobs waiting at a work center queue. The problem has been described as potentially difficult since for a given set of jobs, $\mathrm{m}$, waiting in queue, there are $\mathrm{m}$-factorial ways to sequence those jobs for processing at that work center.

Recent developments in dispatching practice allow web-enabled ERP systems to engage, effortlessly, in information exchange between the company's planning and control system and:

the company's own shop floor;

the company's supplier(s) of raw materials, parts, and components;

the company's customers - both of final product and of parts and components that will be further used in their production of product throughout the supply chain (i.e., B2B).

The dissemination of detailed information about a particular shop order from the ERP database in real time allows shop personnel to concentrate on serving customers while also keeping internal operations efficient (Latamore, 2000). This will almost certainly allow more sophisticated dispatching rules to be employed in a practical settings.

The ultimate goal of dispatching is to develop a schedule for the queue of waiting jobs that results in good shop performance with respect to both efficiency (e.g., flow time statistics) and effectiveness (e.g., consistent due date performance). With the advent of the World Wide Web, information can now be easily exchanged between suppliers and customers and efficiency and effectiveness can be extended throughout the supply chain. It needs to be reiterated, however, that the system for information exchange must insure that the information shared is directly applicable to the dispatching problem and that proprietary information is safeguarded. This is a key relationship between modern-day dispatching and the need for information security - making the right information easily available to others while preventing other information from being exchanged.

The following section will further discuss shop floor dispatching in light of recent advancements in ERP systems and the World Wide Web. Following that discussion, key security issues will be discussed.

\section{RECENT DEVELOPMENTS IN DISPATCHING RESEARCH}

Ovacik and Uzsoy (1994) point out that advancement in shop floor information systems has outpaced dispatching rule research and development. Current shop floor control modules not only have the ability to track the current location of a job and where it needs to go next, but can also determine, with significant accuracy, when the job is expected to arrive at a particular work center, given current shop conditions. Current dispatching practice and research, however, does not take advantage of this readily available and potentially valuable information - particularly when the information is contained in a customer's database. Perhaps one underlying 
reason is the issue of information security.

With respect to job shop dispatching, there is a definite need to further develop and study rules that take advantage of global information readily available via modern ERP systems. In the event that a particular job in queue at a work center is an input to a customer's manufacturing process (i.e., downstream in the supply chain), the global information should be accessed to determine a realistic assessment of priority. Customers should be willing to share the information because of the cost savings resulting from increased efficiency that can potentially be passed along to them as long as proprietary information is not compromised and is unconditionally safeguarded.

\section{DEVELOPMENT OF A SHOP FLOOR DISPATCHING RULE}

As was discussed earlier, shop floor dispatching generally relies on due date information for the control of work flows. In theory, this should provide for good customer service with respect to meeting job due dates. A problem with such an approach, however, may result from congestion at overburdened work centers. If severe, this congestion can ultimately stifle job throughput and increase mean job flow time.

At the other extreme, shop floor dispatching can rely solely on downstream work center conditions when determining which job to run next. For example, if two or more jobs are waiting in queue at a work station, then the job that has the least amount of expected waiting time at its immediate successor operation, based on current downstream queues, is chosen for processing next. Intuitively, this approach should display a low mean job flow time (relative to a rule that relies exclusively on due date information) due to minimum likelihood of congestion and waiting at the downstream operation. The problem with this approach, however, is that without regard for due dates, jobs may either be delivered from the system early or late - neither of which is desirable under a forbidden early shipment constraint.

A shop floor dispatching rule that is classified somewhere in between on the continuum should be sensitive to due dates and to downstream work center conditions (i.e., amount of work currently in queue at the downstream operation). Therefore, a rule must utilize job/operation due date information as well as information about actual shop floor conditions to be considered hybrid. Both pieces of information may in fact come from customer ERP system databases.

\section{SHOP FLOOR DISPATCHING RULE}

The following dispatching rule allows a user to vary the degree to which a decision rule relies on either due date information or shop floor conditions (Busing, 1996). This is important from the standpoint that the decision maker can fine-tune the model to meet his or her own customer service / operating cost objectives.

In order for the model to be successful, however, customer databases must be accessed by supplier firms whenever both of the following conditions are met: 1) a job is at the last operation work center in the supplier company and 2) a job is used as an input to the manufacturing process of the customer's operation (i.e., further value is added before it reaches the customer's immediate successor in the supply chain). The rule requires information to routinely be accessed by supplying firms from a customer database, but should not be allowed if information security for proprietary information cannot be ensured.

The model requires that a shop floor dispatching constant, $\alpha$, be selected $(0 \leq \alpha \leq 1)$. For each job waiting in queue at a particular work center, the following hybrid index is computed:

Dispatching Index $=$

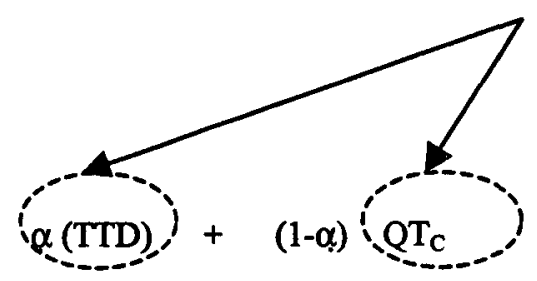

obtained from customer database when job is at last operation in supplying firm's shop

where

$$
\begin{aligned}
& \alpha=\text { shop floor dispatching constant }(0 \leq \alpha \leq 1), \\
& \text { TTD = current operation's due time in hours - current calendar time in hours, and } \\
& Q T_{C}=\text { present amount of work in hours waiting at the job's next operation. }
\end{aligned}
$$

The job with the smallest dispatching index is selected for processing next. A small index is of high priority since it can become small due to a small amount of time remaining until due or due to a small amount of work (i.e., congestion) at the next operation (regardless of whether or not the next operation is internal or that of a customer). In the event of a tie between two or more jobs, shortest operation next (SON) prevails as the decision rule due to its superior queue clearing properties and resulting guarantee of minimum mean flow time for a set of 
jobs at a particular queue. When a job is at its last operation, the values for $Q T_{C}$ and TTD are determined by accessing the customer's database. Specifically, the job is matched with the customer's production schedule to determine which work center or facility will perform further processing in the supplier organization. In the event that the job has no further value added at the customer's organization or is simply a stock-item (to be used later), the dispatching index is exclusively TDD.

This priority dispatching rule can be constructed such that it places more emphasis on operation due dates ( $\square \square$ 1 ), or so that it weights actual shop floor condition information more ( $\square 0$ ). In addition, when $\square=0$, the dispatching rule relies exclusively on downstream shop floor conditions and when $\square=1$, the rule relies exclusively on operation due dates. Thus the model is extremely flexible.

\section{PERFORMANCE MEASUREMENT}

Performance of the shop floor dispatching rules is evaluated with respect to both internal and external criteria. Internal system performance measurement is in terms of the average amount of time a job spends in the system, while external system performance is measured by customer service. Blackstone, Phillips, and Hogg (1982) cite flow time, lateness, and tardiness as measures most often used in evaluating dispatching rule effectiveness in a job shop environment and the proposed rule was evaluated on all three.

\section{Flow time}

Flow time is the amount of time that a job spends in the system. In this study, flow time for an individual job is obtained as follows:

1. record current calendar time when new job is created,

2. record current calendar time when that job finishes processing at its last operation, and

3. (completion time (2) - creation time (1)) is recorded as an observation for each completed job.

The average and standard deviation of flow time was then calculated across all completed jobs for a given simulation run. Flow time is really an indicator of both shop congestion and work-in-process inventory. For example, if two jobs with identical routings and processing times (actual) are run through two separate systems, then the job with the largest flow time clearly experienced more waiting time at its operations due to longer queue delays (congestion) and hence contributed to an increased work-in-process inventory cost for that particular system.

\section{Lateness}

Lateness is defined as an order's completion calendar time minus its published job due time. Since lateness can take on positive or negative values, it is desirable to observe an average lateness statistic close to zero with a minimal standard deviation. That is, on average, orders are neither early nor late.

Since lateness is a function of how job due dates are established, it is necessary that it be considered only as a relative measure of performance for this study. In order to be consistent with other dispatching research (Conway, Johnson, and Maxwell, 1960), a particular shop floor dispatching rule is judged not on an absolute sense or with respect to its ability to achieve a mean lateness statistic close to zero, but rather on its ability to maintain low mean and standard deviation of lateness relative to other shop floor dispatching rules.

\section{Tardiness}

Tardiness is defined as the maximum of either zero or an order's completion calendar time minus its published job due time. Therefore, mean tardiness provides a measure of how late the late jobs are, on average.

This prior study considered mean tardiness in evaluating push, pull, and hybrid shop floor dispatching performance (i.e., the mean lateness of the late jobs only). As is the case with lateness, tardiness is considered only a relative measure of performance among various shop floor dispatching rules.

\section{PERFORMANCE}

There is some preconceived expectation of system performance. First and foremost, it is expected that Krajewski et al. (1987) are correct in stating that environment is important. In good environments (e.g., relatively low shop utilization and low standard processing time variability) any dispatching rule may produce acceptable results. However, as the shop environment becomes more difficult (e.g., extremely high shop 
utilization and high standard processing time variability), it becomes unclear which, if any, of the rules yields acceptable performance.

The type of shop (i.e., job shop versus flow dominant job shop) may prove to significantly affect relative performance of shop floor dispatching rules. For example, a flow dominant job shop is likely to generate temporary congestion at certain key work centers (gateway and finishing) which is not necessarily found in a comparable job shop. Due date sensitive shop floor dispatching rules may be less capable of managing this congestion than are other shop floor dispatching rules. Therefore, due date sensitive shop floor dispatching rules employed in a flow dominant shop are expected to display higher, more variant flow time and lateness statistics and higher tardiness than would the same due date sensitive shop floor dispatching rules employed in a job shop. It remains a bit unclear, however, whether or not all other shop floor dispatching rules (e.g., those that incorporate at least some information about jobs' downstream work center conditions) are affected by a flow dominant shop's congestion in a similar manner.

With respect to specific performance measurement, it is expected that a due-date sensitive shop floor dispatching rule will generally display lower mean lateness and tardiness than shop floor condition sensitive rules, but may yield a higher mean flow time due to congestion at some work centers.

A rule that incorporates both due date information and downstream work center information is expected to produce a significantly lower flow time statistic (mean and standard deviation) than a rule that exclusively utilizes due date information but is expected to yield significantly higher lateness (mean and standard deviation) and tardiness (mean) statistics than rules that exclusively utilize due dates when the shop floor dispatching constant, $\square$, approaches zero. Conversely, the dispatching rule proposed in equation 1 is expected to produce significantly higher flow time statistics than a rule that relies exclusively on shop floor condition information but is expected to yield significantly lower lateness (mean and standard deviation) and tardiness (mean) statistics than a rule that is predominantly due date sensitive. There is also expected to be an optimal value of $\square$ such that the dispatching rule proposed in equation 1 can simultaneously achieve lateness and tardiness statistics that are not significantly different from those of due date sensitive rules and flow time statistics that are not significantly different from those of shop floor condition rules.

\section{INFORMATION SHARING}

This section will propose key customer information that should be easily accessed by suppliers when employing the dispatching rule detailed in equation 1. Following that discussion, a proposal to safeguard other, perhaps proprietary, information contained in ERP databases will be made.

\section{Freely Exchanged Information}

For the model shown in equation 1 to be effectively employed by a supplier firm, specific job related information should be accessible by the supplier's ERP system from the customer's manufacturing database. Specifically, when a job is at the last operation at the supplying firm, the supplier should access the customer's database to determine:

1. whether or not the job requires further value (i.e., processing at the customer site) and if it is required to enter the production process immediately upon arrival at the customer location. If yes to both questions, continue gathering information below. If no to either question, schedule job according to TDD (time until due date);

2. the job's due date at the customer operation;

3. the job's first operation area (via the job's routing file);

4. the amount of work (standard hours) in queue at the job's first operation area.

The above represents the only information that is needed for employment of the model proposed in equation 1 . Furthermore, the above represents the only information that the customer should make available to its supplier.

\section{Secured Information}

In order to protect itself from loss of proprietary information and from threat of forward integration on the part of supplying firms, a customer should ensure that the following information is not made available to a supplier via the World Wide Web.

1. customer's customer contact information and other marketing data;

2. job pricing and costing information;

3. engineering drawings; 
4. bill of materials files;

5. financial data (profit/loss statements, etc.);

6. payroll;

7. employee database and other human resources data;

8. work center or process proprietary information;

9. accounts receivable;

10. accounts payable;

11. inventory.

The above list is by no means exhaustive, but does represent information that absolutely must be protected.

\section{PROTECTING PROPRIETARY INFORMATION}

Since outsiders (i.e., entities other than suppliers of parts and components or those employed by the organization) represent only about 20 percent of the total attack threat (Nichols, Ryan, and Ryan, 2000), this paper will focus on the larger, insider, threat (specifically, suppliers of parts and components). As illustrated above, it is clearly advantageous for a customer to share selected information with suppliers if the result is better shop performance and resulting lower costs that are passed on to the customer in terms of lower prices. However, a customer should also ensure that the proprietary information identified above is not shared with suppliers such that information security is compromised.

Nichols, Ryan and Ryan (2000) identify Access Controls as a means for limiting and managing access to data within an enterprise. Two types of access controls may be employed in order to share appropriate information with supplying firms while prohibiting access to other, proprietary, information. They are discussed below as they relate to protecting customers from a supplying firm's misuse of information.

\section{Role Based Access Control}

In role based access control (RBAC), information within the organization is classified according to subject matter. Those personnel, both inside and outside the organization, are given access to specific information based on the role they play in the organization when RBAC's are employed. For example, with the shop floor dispatching rule mentioned above, a supplier may be given access to shop floor information because of their role as a supplier. However, it should also be noted that the same supplier could conceivably access shop floor information that is not needed to perform the dispatching rule calculation based on their role as a supplier. This information could include work center or process proprietary information if role based access control is the only system in place to manage access to information.

\section{Mandatory Access Control}

Mandatory Access Controls (MAC's) permit or prohibit viewing and transmission of data based on the information's sensitivity within the organization. When RBAC is combined with MAC, a much higher level of security is realized since MAC generally takes priority over RBAC. For example, when the above scenario is again considered with the addition of MAC, a supplier has access to shop floor information because of his/her role in the organization as a supplier and because the firm has a RBAC in place. However, the same supplier may not view the work center or process proprietary information because it is highly sensitive in nature and because a MAC is in place.

\section{CONCLUSION}

This paper has illustrated a practical scenario in enterprise resource planning where two or more firms can benefit from the sharing of information. Specifically, a supplier of parts and components can very likely achieve cost savings by obtaining up to the minute information about a buyer's shop floor conditions when job priority and dispatching decisions need to be made. Some portion of these cost savings can be passed on to the buyer firm. Hence, willingness of both parties to share information should exist. However, with the sharing of selected information comes the need to protect more proprietary information. This paper shows how Role Based Access Control, combined with Mandatory Access Control can facilitate protection of proprietary information. 


\section{REFERENCES}

Blackstone, J.H., Phillips, D.T. \& Hogg, G.L. (1982) “A State-of-the-Art Survey of Dispatching Rules for Manufacturing Job Shop Operations", International Journal of Production Research, Vol. 20, No. 1, pp $27-45$.

Busing, M.E. (1996) "A Comparison of Push, Pull, and Hybrid Approaches to Shop Floor Dispatching", Unpublished Ph.D. Dissertation, Clemson University.

Carroll, D.C. (1965) "Heuristic Sequencing of Single and Multiple Component Jobs", Unpublished Ph.D. Dissertation, Sloan School of Management, M.I.T.

Conway, R.W. (1965) "Priority Dispatching and Work-In-Process Inventory in a Job Shop", Journal of Industrial Engineering, Vol. 16, No. 2, pp 123-130.

Conway, R.W., Johnson, B.M. \& Maxwell, W.L. (1960) "An Experimental Investigation of Priority Dispatching", The Journal of Industrial Engineering, Vol. 11, No. 3, pp 221-229

Day, J.E. \& Hottenstein, M.P. (1970) "Review of Sequencing Research", Naval Research Logistics Quarterly, Vol. 17, pp 11-39.

Fry, D., Philipoom, P.R. \& Blackstone, J.H. (1988) “A Simulation Study of Processing Time Dispatching Rules", Journal of Operations Management, Vol. 7, No. 4, pp 77-92.

Hershauer, J.C. \& Ebert, J. (1974) "Search and Simulation Selection of a Job Shop Scheduling Rule", Management Science, Vol. 21, No. 7, pp 833-843.

Krajewski, L.J., King, B.E., Ritzman, L.P. \& Wong, D.S. (1987) “Kanban, MRP, and Shaping the Manufacturing Environment", Management Science, Vol. 33, No. 1, pp 39-57.

Latamore, GB. (2000) "Using ERP Data to Get [Close] to Customers", APICS: The Performance Advantage, Vol. 10, No. 9, pp 26-30.

Nichols, R.K., Ryan, D.J. \& Ryan, J.J.C.H. (2000) Defending Your Digital Assets, New York: McGraw-Hill Publishing Co.

Ovacik, I.M. \& Uzsoy, R. (1994) "Exploiting Shop Floor Status Information to Schedule Complex Job Shops", Journal of Manufacturing Systems, Vol. 13, No. 2, pp 73-84. 